\title{
Physical activity at work and job responsibility as risk factors for fatal coronary heart disease and other causes of death
}

\author{
A MENOTTI AND F SECCARECCIA \\ From the Laboratory of Epidemiology and Biostatistics, Istituto Superiore di Sanità, Rome, Italy
}

SUMMARY Altogether 99029 men aged 40-59, employed on the Italian railroad system, were classified in three levels of physical activity at work and three levels of job responsibility and then followed up for five years in terms of mortality and cause of death. Physical activity and job responsibility have been investigated in different ways as possible risk factors of lethal events. When considering together the findings of univariate and bivariate analyses it appears that low physical activity and high job responsibility are attributes favouring myocardial infarction, and that high physical activity and low job responsibility are attributes favouring lethal chronic bronchitis and violent death. Overall, mortality from all causes is not significantly different in different classes of physical activity and job responsibility, and within total mortality these two characteristics play a role in the distribution of the various causes of death as a consequence of possible competing risks. A number of other non-measured factors, however, may have had a confounding effect.

The relation between habitual physical activity of working or leisure type and the development of coronary heart disease has been studied in a number of epidemiological investigations during the past 25 to 30 years. ${ }^{1-11}$ Although it is not considered to be a major risk factor, habitual physical activity is at present recognised as a protective factor against the development of atherosclerosis, and coronary events in particular, although in some instances it is partly confounded by other factors.

A long review of the available literature and statements on present knowledge was produced in $1978,{ }^{12} 13$ and some contributions have also been provided by this group. ${ }^{5614}$

The question of responsibility at work is more controversial since such a characteristic is sometimes difficult to define, as are many others of a psychological type which have probably never been studied independently.

At present coronary heart disease seems no longer to be considered the executive's disease, at least in those countries where it was so considered two or three decades ago; the lower social classes are now hit harder by this disease..$^{15} 16$

The problem is obviously confounded by a number of other factors of a similar nature directly or indirectly related to the psychosocial characteristics.
Among these are unfavourable childhood and youth experience, ${ }^{17} 18$ urban lifestyle and residence, excessive employment mobility, ${ }^{16-19}$ hypochondria and emotional instability, ${ }^{20}$ stressful jobs such as taxi and bus driving, etc, ${ }^{21-23}$ high hostility scale levels ${ }^{24}$ and, of course, the classical type A of Jenkins, although at present this is known to be made up of at least four different components. ${ }^{25-29}$

In terms of job responsibility beyond exposure to an excess of external stimuli, it can be assumed that type $A$ individuals are more likely to seek and accept positions of high level responsibility.

Unfortunately, most such factors are ill defined, and a final conclusion cannot be reached by a review of the recent literature; the interpretation is always complicated by the presence of confounding factors. Part of a study, originally designed to investigate the relation of physical activity at work to coronary heart disease, could recently be exploited by this group for a joint evaluation of both physical activity and job responsibility at work.

\section{Material and method}

Altogether 99029 men aged 40-59, employed on the Italian railroad system, were classified according to age (quinquennia), physical activity at work (three 
levels: heavy, moderate, and sedentary), and job responsibility (three levels: high, medium, and low).

In particular, ergonometric studies were carried out in order to attribute average energy expenditure to the several types of work on the railroad. On the basis of such measurements, heavy workers have been defined as those characterised by more than 3000 calories per day; moderate workers 2400 to 3000 calories per day; and sedentary workers less than 2400 calories per day.

Responsibility at work has been evaluated by occupational psychologists who have characterised the several types of job using a score which takes into account the economic and financial implications of decisions taken at work as well as the relevance of possible damage and hazards both economic and for human life as a consequence of possible mistakes made at work.

The classification was made only once at the beginning of the study. For most individuals it reflected the characteristics of jobs undertaken some years before and after that point in time owing to the slow speed and the predefined tracks of careers on the railroad.

A systematic registration of all deaths has been performed on all men including those who had retired in the meanwhile. The coverage has been substantially complete for a period of five years.

Information on deaths and their causes has been obtained from the Central Medical Service of the Railroad, the Board of Pensions, and the Register Offices of the municipalities where the dead persons had their residences. Most of the causes of death have been validated by comparing the official causes with those elicited from hospital and other medical records. The causes of death have been classified according to the 8th Revision of the World Health Organization International classification of diseases, the study having been conducted during the period when this Revision was officially adopted in Italy. ${ }^{30}$
The term coronary heart disease implies a fatal case of myocardial infarction or its early or late complications or sudden death of probable coronary origin.

\section{Results}

Table 1 gives the number of men at risk classified according to five-year age groups. Table 2 shows the same men classified according to three levels of physical activity and three levels of job responsibility. The class corresponding to high job responsibility and high physical activity is empty, and therefore only eight classes will be considered for analysis.

Age standardised death rates (against the whole population as reference) for five years as a function of the three levels of physical activity are shown in table 3.

Table 1 Men at risk classified by five year age groups

\begin{tabular}{|c|c|}
\hline Age (yr) & $N$ \\
\hline $40-44$ & 33122 \\
\hline $45-49$ & 25918 \\
\hline $50-54$ & 30132 \\
\hline $55-59$ & 9857 \\
\hline Total & 99029 \\
\hline
\end{tabular}

Table 2 Men at risk classified by three levels of physical activity and three levels of job responsibility

\begin{tabular}{lrrrrr}
\hline & \multicolumn{4}{l}{ Job responsibility } \\
\cline { 2 - 5 } & Low & Medium & High & Totals \\
\hline Physical activity at work & & & & \\
$\quad$ Sedentary & 2201 & 23728 & 2202 & 28131 \\
$\quad$ Moderate & 1517 & 36046 & 3757 & 41320 \\
Heavy & 25740 & 3838 & - & 29578 \\
Totals & 29458 & 63612 & 5959 & 99029 \\
\hline
\end{tabular}

Table 3 Age standardised death rates per 1000 in five years for all causes and some specific causes of death in men classified by physical activity: Absolute frequencies in parentheses

\begin{tabular}{|c|c|c|c|c|c|c|c|c|c|}
\hline \multirow{2}{*}{\multicolumn{2}{|c|}{ Physical activity }} & \multicolumn{8}{|c|}{ Cause of death } \\
\hline & & \multirow{2}{*}{$\begin{array}{c}\text { All causes } \\
26 \cdot 20 \\
(727)\end{array}$} & \multirow{2}{*}{$\begin{array}{c}\text { Violence } \\
1 \cdot 83 \\
(51)\end{array}$} & \multirow{2}{*}{$\begin{array}{l}\begin{array}{l}\text { Myocardial } \\
\text { infarction }\end{array} \\
7 \cdot 70 \\
(210)\end{array}$} & \multirow{2}{*}{$\begin{array}{l}\text { Stroke } \\
2 \cdot 20 \\
(61)\end{array}$} & \multirow{2}{*}{$\begin{array}{l}\begin{array}{l}\text { Other } C V \\
\text { diseases }\end{array} \\
1 \cdot 52 \\
(42)\end{array}$} & \multirow{2}{*}{$\begin{array}{l}\begin{array}{l}\text { Chronic } \\
\text { bronchitis }\end{array} \\
0.18 \\
(5)\end{array}$} & \multirow{2}{*}{$\begin{array}{l}\text { Cancer } \\
7 \cdot 83 \\
(217)\end{array}$} & \multirow{2}{*}{$\begin{array}{l}\text { All other causes } \\
4.94 \\
(141)\end{array}$} \\
\hline Sedentary & (S) & & & & & & & & \\
\hline Moderate & (M) & $\begin{array}{l}27.05 \\
(1136)\end{array}$ & $\begin{array}{l}2 \cdot 86 \\
(120)\end{array}$ & $\begin{array}{l}7 \cdot 50 \\
(292)\end{array}$ & $\begin{array}{l}1.44 \\
(61)\end{array}$ & $\begin{array}{l}1 \cdot 52 \\
(64)\end{array}$ & $\begin{array}{l}0.40 \\
(17)\end{array}$ & $\begin{array}{l}8 \cdot 50 \\
(358)\end{array}$ & $\begin{array}{l}4 \cdot 83 \\
(224)\end{array}$ \\
\hline Heavy & (H) & $\begin{array}{c}27 \cdot 35 \\
(798)\end{array}$ & $\begin{array}{l}4.40 \\
(129)\end{array}$ & $\begin{array}{l}4.90 \\
(112)\end{array}$ & $\begin{array}{l}2 \cdot 21 \\
(65)\end{array}$ & $\begin{array}{l}2 \cdot 29 \\
(67)\end{array}$ & $\begin{array}{l}0.72 \\
(21)\end{array}$ & $\begin{array}{l}7 \cdot 57 \\
(220)\end{array}$ & $\begin{array}{l}5 \cdot 56 \\
(184)\end{array}$ \\
\hline \multicolumn{10}{|c|}{ p of test on proportion } \\
\hline$S \vee M$ & & ns & $<0.01$ & ns & $<0.05$ & ns & ns & ns & ns \\
\hline $\mathbf{S} v \mathbf{H}$ & & ns & $<0.001$ & $<0.001$ & & $<0.05$ & $<0.01$ & ns & ns \\
\hline $\mathbf{M} \boldsymbol{v} \mathbf{H}$ & & ns & $<0.001$ & $<0.001$ & $<0.05$ & $<0.05$ & ns & ns & ns \\
\hline
\end{tabular}


Overall mortality from all causes is not substantially different between the three groups; on the other hand, people with sedentary or moderately active jobs show an excess of deaths from myocardial infarction, which is largely compensated by an excess of violent deaths in very active people. Moreover, heavy workers have an excess of deaths from other heart disease and from chronic bronchitis and allied conditions.

A similar tabulation (table 4) shows death rates as a function of job responsibility. In particular, violent deaths are more common among people with low than with high responsibility, whereas the opposite is the case for myocardial infarction.

In table 5 death rates for the same causes are reported for men classified in combined classes of physical activity and job responsibility. The variability among classes is greater than in the previous two tables. The high and low levels are as follows:

All causes-high in heavy workers with medium responsibility;

All causes-low in sedentary people with medium responsibility;

Violence-high in heavy workers with low responsibility;
Violence-low in sedentary people with high responsibility;

Myocardial infarction-high in sedentary people with high responsibility;

Myocardial infarction-low in physically moderate workers with low responsibility;

Stroke-high in heavy workers with medium responsibility;

Stroke-low in physically moderate workers with medium responsibility;

Other cardiovascular-high in physically moderate workers with medium responsibility;

Other cardiovascular-low in sedentary people with high responsibility;

Chronic bronchitis-high in heavy workers with medium responsibility;

Chronic bronchitis-low in sedentary people with low and high responsibility (zero) and in physically moderate people with low responsibility;

Cancer-high in physically moderate people with high responsibility;

Table 4 Age standardised death rates per 1000 in five years for all causes and some specific causes of death in men classified by job responsibility: Absolute frequencies in parentheses

\begin{tabular}{|c|c|c|c|c|c|c|c|c|c|}
\hline & & \multicolumn{8}{|c|}{ Cause of death } \\
\hline \multicolumn{2}{|c|}{ Job responsibility } & All causes & Violence & $\begin{array}{l}\text { Myocardial } \\
\text { infarction }\end{array}$ & Stroke & $\begin{array}{l}\text { Other } C V \\
\text { diséases }\end{array}$ & $\begin{array}{l}\text { Chronic } \\
\text { bronchitis }\end{array}$ & Cancer & All other causes \\
\hline Low & (L) & $\begin{array}{c}27 \cdot 28 \\
(798)\end{array}$ & $\begin{array}{l}4.08 \\
(120)\end{array}$ & $\begin{array}{r}5.00 \\
(125)\end{array}$ & $\begin{array}{c}2.01 \\
(59)\end{array}$ & $\begin{array}{l}2.52 \\
(74)\end{array}$ & $\begin{array}{l}0.62 \\
(18)\end{array}$ & $\begin{array}{l}7 \cdot 55 \\
(220)\end{array}$ & $\begin{array}{l}5.50 \\
(182)\end{array}$ \\
\hline Medium & (M) & $\begin{array}{l}26.78 \\
(1712)\end{array}$ & $\begin{array}{l}2.67 \\
(171)\end{array}$ & $\begin{array}{c}7.30 \\
(427)\end{array}$ & $\begin{array}{l}1.85 \\
(118)\end{array}$ & $\begin{array}{l}1.41 \\
(90)\end{array}$ & $\begin{array}{l}0.38 \\
(24)\end{array}$ & $\begin{array}{l}8.35 \\
(536)\end{array}$ & $\begin{array}{l}4.68 \\
(346)\end{array}$ \\
\hline High & (H) & $\begin{array}{r}26 \cdot 45 \\
(151)\end{array}$ & $\begin{array}{r}1.57 \\
(9)\end{array}$ & $\begin{array}{r}11 \cdot 30 \\
(62)\end{array}$ & $\begin{array}{c}1.91 \\
(10)\end{array}$ & $\begin{array}{r}1.61 \\
(9)\end{array}$ & $\begin{array}{r}0.22 \\
(1)\end{array}$ & $\begin{array}{c}6.80 \\
(39)\end{array}$ & $\begin{array}{c}4.65 \\
(21)\end{array}$ \\
\hline \multicolumn{10}{|c|}{$p$ of test on proportion } \\
\hline $\begin{array}{l}L \vee M \\
L \vee V H \\
M \vee H\end{array}$ & & $\begin{array}{l}\text { ns } \\
\text { ns } \\
\text { ns }\end{array}$ & $\begin{array}{l}<0.001 \\
<0.01 \\
\text { ns }\end{array}$ & $\begin{array}{l}<0.001 \\
<0.001 \\
<0.001\end{array}$ & $\begin{array}{l}<0.001 \\
\text { ns } \\
\text { ns }\end{array}$ & $\begin{array}{l}\text { ns } \\
\text { ns } \\
\text { ns }\end{array}$ & $\begin{array}{l}\text { ns } \\
\text { ns } \\
\text { ns }\end{array}$ & $\begin{array}{l}\text { ns } \\
\text { ns } \\
\text { ns }\end{array}$ & $\begin{array}{l}\text { ns } \\
\text { ns } \\
\text { ns }\end{array}$ \\
\hline
\end{tabular}

Table 5 Age standardised death rates per 1000 in five years for all causes and some specific causes of death in men classified in eight combined classes of physical activity and job responsibility

\begin{tabular}{|c|c|c|c|c|c|c|c|c|c|}
\hline \multirow[b]{2}{*}{$\begin{array}{l}\text { Physical } \\
\text { activity }\end{array}$} & \multirow[b]{2}{*}{$\begin{array}{l}\text { Job } \\
\text { responsibility }\end{array}$} & \multicolumn{8}{|c|}{ Cause of death } \\
\hline & & All causes & Violence & $\begin{array}{l}\text { Myocardial } \\
\text { infarction }\end{array}$ & Stroke & $\begin{array}{l}\text { Other } C V \\
\text { diseases }\end{array}$ & $\begin{array}{l}\text { Chronic } \\
\text { bronchitis }\end{array}$ & Cancer & All other causes \\
\hline $\begin{array}{l}\text { Sedentary } \\
\text { Sedentary } \\
\text { Sedentary } \\
\text { Moderate } \\
\text { Moderate } \\
\text { Moderate } \\
\text { Heavy } \\
\text { Heavy }\end{array}$ & $\begin{array}{l}\text { Low } \\
\text { Medium } \\
\text { High } \\
\text { Low } \\
\text { Medium } \\
\text { High } \\
\text { Low } \\
\text { Medium }\end{array}$ & $\begin{array}{l}30 \cdot 00 \\
25 \cdot 20 \\
25 \cdot 80 \\
26 \cdot 30 \\
28 \cdot 50 \\
25 \cdot 80 \\
26 \cdot 90 \\
30 \cdot 80\end{array}$ & $\begin{array}{l}1 \cdot 21 \\
1 \cdot 93 \\
1 \cdot 13 \\
2 \cdot 07 \\
3 \cdot 04 \\
1 \cdot 93 \\
4 \cdot 53 \\
3.45\end{array}$ & $\begin{array}{r}9 \cdot 70 \\
7 \cdot 20 \\
11 \cdot 60 \\
3 \cdot 80 \\
7 \cdot 50 \\
10 \cdot 20 \\
4 \cdot 80 \\
5.00\end{array}$ & $\begin{array}{l}2 \cdot 84 \\
2 \cdot 17 \\
1 \cdot 51 \\
2 \cdot 64 \\
1 \cdot 34 \\
2 \cdot 16 \\
1 \cdot 85 \\
5 \cdot 29\end{array}$ & $\begin{array}{l}3 \cdot 03 \\
1 \cdot 44 \\
0 \cdot 47 \\
3 \cdot 08 \\
1 \cdot 35 \\
2 \cdot 46 \\
2 \cdot 38 \\
1 \cdot 92\end{array}$ & $\begin{array}{l}\overline{0.21} \\
- \\
\overline{0.41} \\
0.43 \\
0.73 \\
1.04\end{array}$ & $\begin{array}{r}6.77 \\
8.59 \\
2.00 \\
8.79 \\
8.40 \\
10.64 \\
7.50 \\
7.51\end{array}$ & $\begin{array}{l}6 \cdot 45 \\
3 \cdot 66 \\
9 \cdot 09 \\
5 \cdot 92 \\
6 \cdot 46 \\
2 \cdot 02 \\
5 \cdot 11 \\
6 \cdot 59\end{array}$ \\
\hline
\end{tabular}


Cancer-low in sedentary people with high responsibility;

All other causes-high in sedentary people with high responsibility;

All other causes-low in physically moderate people with high responsibility.

The overall picture emerging from table 5 suggests that some combinations of physical activity and job responsibility tend to favour or to protect against some diseases, although the overall final differences in terms of diseases from all causes are relatively small. The interest in trying to estimate the combined effect of physical activity and job responsibility is clear, and several techniques can be employed.

The rates in tables 3 and 4 (univariate analysis for physical activity and job responsibility separately) have been recomputed (but not reported here) by adjusting for the other characteristics' distributions. The net result has been that the overall picture has not changed substantially.

Another attempt, presented in table 6, has been made by taking the eight combined activity-responsibility classes and solving a bivariate equation for each fatal endpoint, where $y$ is the considered disease, $x_{1}$ is the "score" for physical activity and $x_{2}$ the "score" for job responsibility. Such scores have been arbitrarily given the levels of 1,2 , and 3 for sedentary, moderate, and heavy physical activity; and low, medium, and high job responsibility respectively.

The data suggest the following:

(1) All coefficients of physical activity are positive except that concerning myocardial infarction.

(2) All coefficients of job responsibility are negative except that concerning chronic bronchitis.

(3) Only two coefficients yield statistical significance being different from zero with a chance of $99 \%$ or more.

(4) Only three $R^{2}$ (the square of the multiple correlation coefficients) explain a substantial proportion (at least 50\%) of the variance of death rates as a function of the two considered characteristics; they refer to violent deaths, myocardial infarction, and chronic bronchitis.

\section{Comment}

The available data and results suggest that both characteristics, physical activity and job responsibility, although somewhat inversely related, may play an independent role in the prediction of fatal events.

However, since the overall death rates for all causes are relatively homogeneous among the several
Table 6 Regression equations of mortality from various causes on physical activity and job responsibility

\begin{tabular}{llll}
\hline Cause of death & \multicolumn{2}{l}{ Equation } & $R^{2}$ \\
\hline All causes & $y=27.45+0.68$ & PA-0.70 JR & 0.18 \\
Violence & $y=0.52+1.21^{* *}$ PA-0.20 JR & 0.82 \\
Myocardial infarction & $y=7.60-1.88$ & PA-1.82 JR & 0.73 \\
Stroke & $y=1.52+0.61$ & PA-0.10 JR & 0.18 \\
Other CV diseases & $y=3.10+0.12$ & PA-0.70 JR & 0.47 \\
Chronic bronchitis & $y=0.63+0.42^{* *}$ & PA+0.11 JR & 0.79 \\
Cancer & $y=6.38+0.98$ & PA-0.37 JR & 0.14 \\
All other causes & $y=6.42+1.08$ & PA-1.43 JR & 0.56 \\
\hline
\end{tabular}

${ }^{* *} \mathrm{p}<0.05$.

classes, their impact seems to relate mainly in favouring (or protecting against) one instead of another cause of death.

There are several ways of interpreting such findings. Firstly, the possibility cannot be ruled out that the different social classes identified by different levels of physical activity and job responsibility may receive, for some reason, different types of diagnoses. However, it is difficult to argue that this would be so systematic as to distort all disease classification.

Another possibility is that dealing with a typical situation of competing risks, ie, being for some direct or indirect reason protected against a disease means, at the same time, being more prone or simply more exposed to others, and vice versa. Two peculiar situations are mentioned. It is known that the class"sedentary with low responsibility" includes a proportion of men who moved from other classes because of some already manifest disease. This may explain part of the excess mortality in this class, but the type of classification made once for all should limit the impact of this possibility. Heavy workers, on the other hand, with either low or medium job responsibility exhibit the highest death rate from violent causes. This means that, excluding the non-natural causes, their overall death rates would be closer to those of the sedentary people, that is, 22.95 per 1000 for heavy workers, 24.19 per 1000 for physically moderate workers, and $24 \cdot 37$ per 1000 for sedentary people. On the other hand, the excess mortality from violent causes is not fully explained by the specific occupational hazards of those having high physical activity, and this group shows a lower death rate for "natural causes".

Apart from the doubts and the uncertainties raised by these notes the impression remains that job characteristics are associated with fatal disease distribution, although a more thorough approach is needed in order to clarify several points, especially the possibility of effects due to competing risks. 


\section{References}

${ }^{1}$ Morris JN, Chave SPW, Adam C, Sirey C, Epstein L. Vigorous exercise in leisure-time and the incidence of coronary heart disease. Lancet 1973; i: 333-9.

${ }^{2}$ Paffenbarger RS, Hale WE. Work activity and coronary heart mortality. $N$ Engl J Med 1975; 292: 545-50.

${ }^{3}$ Taylor HL, Klepetar E, Keys A, Parlin W, Blackburn H, Puchner TC. Death rates among physically active and sedentary employees of the railroad industry. Am J Publ Hlth 1962; 52: 1967-76.

${ }^{4}$ Puchner TC, Blackburn HW, Taylor HL, Keys A. Coronary heart disease among physically active and sedentary employees of the railroad industry. Circulation 1961; 24: 1016-7.

${ }^{5}$ Menotti A, Puddu V. Death rates among the Italian railroad employees with special reference to coronary heart disease and physical activity at work. Environ Res 1976; 11: 331-42.

${ }^{6}$ Menotti A, Puddu V. Ten-year mortality for coronary heart disease in 172,000 men classified by physical activity at work. Scand J Work Environ Health 1979; 5: 100-8.

${ }^{7}$ Salonen JT, Puska P, Tuomilehto J. Physical activity and risk of myocardial infarction, cerebral stroke and death: a longitudinal study in Eastern Finland. Am J Epidemiol 1982; 115: 526-37.

${ }^{8}$ Dawber TR. The Framingham study. The epidemiology of atherosclerotic disease. Cambridge, Mass, and London, England: Harvard University Press, 1980; 1-257.

${ }^{9}$ Hickey N, Mulcahy R, Bourke GJ, Graham I, Wilson Davis K. Study of coronary risk factors related to physical activity in 15,171 men. $B r \operatorname{Med} J$ 1975; 3: 507-9.

${ }^{10}$ Keys A, Menotti A, Aravanis C, et al. The seven countries study: 2289 deaths in 15 years. Prev Med 1984; 13: 141-54.

${ }^{11}$ Keys A, Aravanis C, Blackburn $\mathrm{H}$, et al. Seven countries. A multivariate analysis of death and coronary heart disease. Cambridge, Mass, and London, England: Harvard University Press, 1980; 1-381.

${ }^{12}$ European Economic Commission: Report of the joint EEC/WHO workshop on physical activity in primary prevention of ischaemic heart disease. Luxembourg, 22-24 February 1977, EEC, Luxembourg, 1978.

${ }^{13}$ WHO. Habitual physical activity and health. WHO Regional Publications. European Series n.6. Copenhagen: WHO Regional Office for Europe, 1978.

${ }^{14}$ Italian Research Group of the Seven Countries Study: Incidence and prediction of coronary heart disease in two Italian rural population samples followed-up for 20 years. Acta Cardiol 1982; 37: 129-45.
${ }^{15}$ Howell RW. Social class and biological tests. Lancet 1970; i: 1343 .

${ }^{16}$ Syme SL, Hyman MM, Enterline PE. Some social and cultural factors associated with the occurrence of coronary heart disease. J Chron Dis 1964; 17: 277-89.

${ }^{17}$ Theorell T, Lind E, Floderns B. The relationship of disturbing life-changes and emotions on the early development of myocardial infarction and other serious illness. Int J Epidemiol 1978; 4: 281-93.

${ }^{18}$ Theorell T. Psychosocial factors and myocardial infarction. Why and how? Advanc Cardiol 1973; 8: 117-31.

${ }^{19}$ Alfredsson L, Karasek R, Theorell T. Myocardial infarction risk and psychosocial work environment: an analysis of the male Swedish working force. Soc Sc Med 1982; 16: 463-7.

${ }^{20}$ Ostfeld AM, Lebovits BZ, Shekelle RB, Paul O. A prospective study of the relationship between personality and coronary heart disease. J Chron Dis 1964; 17: 265-76.

${ }^{21}$ Holme I, Helgeland A, Hjerman I, Leren $P$. Socio-economic status on a coronary risk factor. The Oslo Study. Acta Med Scand 1982; 660: 147-51.

${ }^{22}$ Holme I, Helgeland A, Hjerman I, Leren P, Lund-Larsen PG. Coronary risk factors in various occupational groups. The Oslo Study. Brit J Prev Soc Med 1977; 31: 96-100.

${ }^{23}$ Holme I, Helgeland A, Hjerman I, Lund-Larsen PG, Leren $P$. Coronary risk factors and socio-economic status. The Oslo Study. Lancet 1976; ii: 1396-8.

${ }^{24}$ Shekelle RB, Gale M, Ostfeld AM, Paul O. Hostility, risk of coronary heart disease and mortality. Psychosom Med 1983; 45: 109-14.

${ }^{25}$ Jenkins CD. Psychosocial risk factors for coronary heart disease. Acta Med Scand 1982; 660: Supp, 123-36.

${ }^{26}$ Shekelle RB, Schoenberger JA, Stamler J. Correlates of the JAS type A behaviour pattern score. J Chron Dis 1976; 29: 381-94.

${ }^{27}$ Rosenman RH, Brand RJ, Jenkins D, Friedman M, Straus $R$, Wurm M. Coronary heart disease in the Western collaborative group study. Final follow-up experience of 8.5 year. JAMA 1975; 233: 872-7.

${ }^{28}$ Haynes SG, Feinleib M, Kannel WB. The relationship of psychosocial factors to coronary heart disease in the Framingham Study. Am J Epidemiol 1980; 111: 37-58.

${ }^{29}$ Mattews KA, Glass DC, Rosenman RH, et al. Competitive drive, pattern $A$ and coronary heart disease: a further analysis of some data from the Western Collaborative Group Study. J Chron Dis 1977; 30: 489-98.

${ }^{30}$ World Health Organization. Manual of the international statistical classification of diseases, injuries and causes of death, vol I, Eighth Revision. Geneva: WHO, 1967. 
Parents' and professionals' attitudes to measles immunisation

A Lakhani, R Morris, M Morgan, C Dale, and M Vaile Department of Community Medicine, St Thomas' Hospital Medical School, London

The evaluation of the South Manchester Family Worker Scheme

B Spencer and J Morris

Department of Epidemiology and Social Research, University Hospital of South Manchester, Manchester
Ethnic minorities and the cost of care in the community M R Baker and E E M Kernohan

Clinical Epidemiology Research Unit, University of Bradford

During the meeting members of the Open University gave a guest presentation entitled "Health and Disease: A New Open University Course”.

\section{Corrections}

In the paper by Shunichi Araki and Yoshitaka Goto $(1985 ; 39: 82-5)$ the heading of the last column in Table 1 should read 'Total'.

In the paper by A Menotti and F Seccareccia (1985; 39: 325-9) the third line of Table 6 should read: Myocardial infarction $y=7 \cdot 60-1 \cdot 88 \mathrm{FA}+1 \cdot 82 \mathrm{JR}$ 0.73 . The footnote to Table 6 should read: ${ }^{* *} \mathrm{p}<0 \cdot 01$. In the left-hand column of page 328 , line 34 should read: (2) All coefficients of job responsibility are negative except that concerning chronic bronchitis and myocardial infarction. 